\section{(C) OPEN ACCESS}

\title{
Outcomes from stereotactic surgery for essential tremor
}

\author{
Robert Francis Dallapiazza, ${ }^{1}$ Darrin J Lee, ${ }^{1}$ Philippe De Vloo, ${ }^{1}$ Anton Fomenko, ${ }^{1}$ \\ Clement Hamani, ${ }^{1}$ Mojgan Hodaie, ${ }^{1}$ Suneil K Kalia, ${ }^{1}$ Alfonso Fasano, ${ }^{2,3,4}$ \\ Andres M Lozano ${ }^{1}$
}

\begin{abstract}
- Additional material is
published online only. To view please visit the journal online (http://dx.doi.org/10.1136/ jnnp-2018-318240).

${ }^{1}$ Division of Neurosurgery, University of Toronto, Toronto, Ontario, Canada

${ }^{2}$ Edmond J. Safra Program in Parkinson's Disease, Morton and Gloria Shulman Movement Disorders Clinic, Toronto Western Hospital, Toronto, Ontario, Canada

${ }^{3}$ Division of Neurology, University of Toronto, Toronto, Ontario, Canada

${ }^{4}$ Krembil Research Institute, Toronto, Ontario, Canada
\end{abstract}

\section{Correspondence to}

Dr Robert Francis Dallapiazza, Division of Neurosurgery, Toronto Western Hospital, Toronto, ON M5T 258, Canada; rfdallapiazza@gmail.com

Received 16 February 2018 Revised 17 July 2018 Accepted 25 September 2018 Published Online First 18 October 2018

\section{ABSTRACT}

There are several different surgical procedures that are used to treat essential tremor (ET), including deep brain stimulation (DBS) and thalamotomy procedures with radiofrequency (RF), radiosurgery (RS) and most recently, focused ultrasound (FUS). Choosing a surgical treatment requires a careful presentation and discussion of the benefits and drawbacks of each. We conducted a literature review to compare the attributes and make an appraisal of these various procedures. DBS was the most commonly reported treatment for ET. One-year tremor reductions ranged from $53 \%$ to $63 \%$ with unilateral Vim DBS. Similar improvements were demonstrated with RF (range, 74\%-90\%), RS (range, 48\%-63\%) and FUS thalamotomy (range, 35\%-75\%). Overall, bilateral Vim DBS demonstrated more improvement in tremor reduction since both upper extremities were treated (range, 66\%-78\%). Several studies show continued beneficial effects from DBS up to five years. Long-term follow-up data also support RF and gamma knife radiosurgical thalamotomy treatments. Quality of life measures were similarly improved among patients who received all treatments. Paraesthesias, dysarthria and ataxia were commonly reported adverse effects in all treatment modalities and were more common with bilateral DBS surgery. Many of the neurological complications were transient and resolved after surgery. DBS surgery had the added benefit of programming adjustments to minimise stimulation-related complications. Permanent neurological complications were most commonly reported for RF thalamotomy. Thalamic DBS is an effective, safe treatment with a long history. For patients who are medically unfit or reluctant to undergo DBS, several thalamic lesioning methods have parallel benefits to unilateral DBS surgery. Each of these surgical modalities has its own nuance for treatment and patient selection. These factors should be carefully considered by both neurosurgeons and patients when selecting an appropriate treatment for ET.

\section{Check for updates}

(C) Author(s) (or their employer(s)) 2019. Re-use permitted under CC BY-NC. No commercial re-use. See rights and permissions. Published by BMJ.

To cite: Dallapiazza RF, Lee DJ, De Vloo P, et al. J Neurol Neurosurg Psychiatry

2019:90:474-482

\section{INTRODUCTION}

Essential tremor (ET) is a debated, heterogeneous entity that is historically considered the most common movement disorder in adults with an estimated prevalence of $0.5 \%-5 \% .^{12}$ ET typically presents with kinetic, intention and/or postural tremor that symmetrically affects the upper extremities, although variable involvement of the neck, face, vocal cords and lower extremities can be seen. ${ }^{34}$ ET is not a life-threatening condition; however, it can profoundly impact the quality of life in patients with severe symptoms. ${ }^{56}$ Patients report difficulty with everyday tasks such as eating, drinking, handwriting and dressing. Many patients also experience social embarrassment regarding their tremor. Some will refrain from dining in public, and others will retire from employment early due to disabling symptoms.

Medical therapy is the first-line treatment for ET (particularly beta-blockers and primidone). ${ }^{7}$ However, medications alone are often insufficient to control severe symptoms and can have undesirable side effects. ${ }^{8}$ Currently, there are four effective surgical treatments for patients with ET. Most surgical interventions target the ventral intermediate nucleus (Vim) of the thalamus and the adjacent ventral white matter tracts. ${ }^{8}$ The purpose of this review is to present the existing literature regarding outcomes of the four commonly performed surgical treatments for ET: (1) deep brain stimulation (DBS), (2) radiofrequency (RF) thalamotomy, (3) gamma knife radiosurgical (GKRS) thalamotomy and (4) focused ultrasound (FUS) thalamotomy (table 1) and to provide a procedural comparison (table 2). This information provides a useful platform for clinicians and patients to review and discuss the nuances of the various surgical treatments for ET.

\section{METHODS}

In this review, we follow the Preferred Reporting Items for Systematic Reviews and Meta-Analysis (PRISMA) standards. We searched Pubmed (1946October 2017) by using both controlled vocabulary words and synonymous free text words for both the indication (ET) and treatment modalities (RF ablation, DBS, stereotactic radiosurgery (RS), FUS). The search was not limited by study design or language. Studies with unblinded and blinded assessments of outcome were included. Studies that reported results from five or more patients using a standard ET severity scale were included.

The primary objective was the assessment of efficacy and safety of the different modalities in the treatment of ET. The secondary objective was the assessment of the treatment outcome on the activities of daily living (ADLs) and the quality of life. The primary efficacy outcome was the difference in tremor before and after treatment. We examined studies that report tremor improvement according to the Fahn-Tolosa-Marin rating scale, the tremor subsection of the Unified Parkinson's Disease 
Table 1 A comparison of surgical outcomes for ET

\begin{tabular}{|c|c|c|c|c|}
\hline & DBS & FUS & GKRS & RF \\
\hline Experience & $\begin{array}{l}1093 \text { patients } \\
\text { since } 1998\end{array}$ & $\begin{array}{l}151 \text { patients } \\
\text { since } 2013\end{array}$ & $\begin{array}{l}360 \text { patients } \\
\text { since } 2007\end{array}$ & $\begin{array}{l}278 \text { patients } \\
\text { since } 1986\end{array}$ \\
\hline $\begin{array}{l}\text { Level of Evidence, } \\
\text { (OCEM) }\end{array}$ & Level 2 & Level 1 & Level 4 & Levels 2-4 \\
\hline $\begin{array}{l}\text { Tremor control, } \\
12 \text {-month follow- } \\
\text { up }\end{array}$ & $\begin{array}{l}\text { Unilateral: } \\
53.4 \%-62.8 \% \\
\text { Bilateral } \\
66 \%-78 \%\end{array}$ & $\begin{array}{l}\text { Unilateral: } \\
35 \%-75 \% \\
\text { Bilateral: no } \\
\text { data }\end{array}$ & $\begin{array}{l}\text { Unilateral: } \\
48 \%-63 \% \\
\text { Bilateral: no } \\
\text { data }\end{array}$ & $\begin{array}{l}\text { Unilateral: } \\
74 \%-90 \% \\
\text { Bilateral: no } \\
\text { data }\end{array}$ \\
\hline $\begin{array}{l}\text { Tremor control, } \\
\text { long-term follow- } \\
\text { up }\end{array}$ & $\begin{array}{l}\text { Unilateral: } \\
60 \%-75 \% \\
\text { Bilateral } \\
75 \%\end{array}$ & $\begin{array}{l}\text { Unilateral: } \\
56 \%\end{array}$ & $\begin{array}{l}\text { Unilateral: } \\
3 \%-63 \%\end{array}$ & $\begin{array}{l}\text { Unilateral: } \\
74 \%-90 \%\end{array}$ \\
\hline $\begin{array}{l}\text { Quality of life } \\
\text { improvements }\end{array}$ & $57.9 \%-82 \%$ & $37 \%-73 \%$ & $65 \%$ & $47 \%$ \\
\hline $\begin{array}{l}\text { Complications } \\
\text { (range, transient } \\
\text { and permanent) }\end{array}$ & $\begin{array}{l}\text { Unilateral, } \\
\text { bilateral }\end{array}$ & & & \\
\hline Dysarthria & $\begin{array}{l}11 \%-39 \% \\
22 \%-75 \%\end{array}$ & $3 \%$ & $1 \%-3 \%$ & $4.6 \%-29 \%$ \\
\hline Ataxia/gait & $\begin{array}{l}9 \%-17 \% \\
56 \%-86 \%\end{array}$ & $23 \%$ & $0 \%-17 \%$ & $5 \%-27 \%$ \\
\hline Paraesthesia & $5 \%, 5.9 \%$ & $14 \%-25 \%$ & $1 \%-9 \%$ & $6 \%-42 \%$ \\
\hline Hemiparesis & $4.5 \%, 6.7 \%$ & $2 \%-7 \%$ & $0 \%-8 \%$ & $0 \%-34 \%$ \\
\hline
\end{tabular}

ET, essential tremor; DBS, deep brain stimulation; FUS, focused ultrasound; GKRS, gamma knife radiosurgical thalamotomy; RF, radiofrequency.

Rating Scale and/or the Unified Tremor Rating Scale. The primary safety outcome was the frequency, types and severity of the adverse events following the different treatment modalities. All searches were conducted on 1 October 2017. Further studies were retrieved by examining the references of the included articles.

\section{RESULTS}

Deep brain stimulation for essential tremor

First reported in the late 1980s, DBS has become the most common surgical procedure for ET and was approved by the Food and Drug Administration (FDA) in 1997. The intranuclear Vim/Vop ventrolateral thalamus is the traditional target for ablative procedures and neuromodulation in ET, which receives unconscious proprioceptive information from the cerebellar dentate nucleus via the dentatorubrothalamic tract (figure 1). Within the Vim nucleus, cells that fire synchronously with the patients' tremor can be electrically recorded, and disruption of this activity has long been known to arrest tremor.

Vim thalamic DBS surgery is typically performed under local anaesthesia but can also be performed under general anaesthesia. A frontal burr hole is drilled, and thalamic intracranial electrodes are implanted. Microelectrode recordings for target mapping can be used to refine the final electrode placement. Macroelectrode stimulation can further facilitate optimisation of the target and clinical benefit and establish the presence of stimulation-induced side effects. Once in place, electrodes are secured to the skull and extension wires are used to connect the intracranial electrodes to an implanted pulse generator under general anaesthesia. The tremor suppressive effects of acute DBS are immediately evident.

We included 53 case series of DBS for ET ( 40 case series of Vim DBS, 13 cases of posterior subthalamic area/caudal zona incerta (PSA/cZI) DBS). These reports include 1093 patients (913 Vim, $180 \mathrm{PSA} / \mathrm{cZI})$. A majority of operations were performed unilaterally (637 Vim, $121 \mathrm{PSA} / \mathrm{cZI}$ ) compared with bilaterally (276 Vim, $59 \mathrm{PSA} / \mathrm{cZI}$ ). Bilateral procedures were mostly performed during a single procedure.

Several studies have shown that unilateral Vim DBS reduces overall tremor at 12 months. With unilateral Vim DBS, the overall tremor reduction that was reported ranged from $53.4 \%$ to $62.8 \%$ (online supplementary table 1 ). Action tremor involving the contralateral upper extremities was markedly improved with unilateral DBS with a reduction of tremor scores ranging from $38.2 \%$ to $78.9 \% .^{9}{ }^{10}$ At longer follow-up out to 5 years, data demonstrated excellent contralateral upper extremity action tremor reduction $(60.3 \%-75 \%)$ among patients with unilateral Vim DBS. ${ }^{1112}$ Blomstedt et al reported a $60.3 \%$ reduction in contralateral upper extremity tremor at an average follow-up time of 86 months among 19 patients who received unilateral DBS. Thalamic DBS also improved ADLs by $57.9 \%-82 \%$ among patients with unilateral DBS at 1 year. ${ }^{13-15}$ ADL improvement after 5 years ranged from $32.3 \%$ to $51 \% .^{11} 1214$

Further studies suggested that bilateral Vim DBS was safe and led to greater overall tremor reduction since both sides of the body were treated. Bilateral Vim DBS reduces overall tremor by 66\%-78\% (online supplementary table 1). ${ }^{9} 1012141617$ In addition, bilateral Vim DBS showed better improvement for axial and head/neck tremor ${ }^{15} 1819$ and voice tremor. ${ }^{15}{ }^{19}$ In 1999 , Koller et $a l^{20}$ reported a series of 38 patients and noted that all patients with head tremor had some improvement with unilateral Vim DBS. Hagglund et $a l^{21}$ reported a 50\% improvement

\begin{tabular}{|c|c|c|c|c|}
\hline & DBS & FUS & GKRS & RF \\
\hline Frame application & $\begin{array}{l}\text { Yes } \\
{ }^{*} \text { Can be performed framelessly }\end{array}$ & Yes & Yes & Yes \\
\hline Hair removal & Partial & Completely & None & Partial \\
\hline Cranial burr hole & Yes & No & No & Yes \\
\hline Target confirmation & $\begin{array}{l}\text { MER, electrical stimulation, } \\
\text { procedural evaluation }\end{array}$ & Test lesions, procedural evaluations & Indirect anatomical targeting & $\begin{array}{l}\text { MER, electrical stimulation, test } \\
\text { lesions, procedural evaluations }\end{array}$ \\
\hline Treatment effects & Immediate & Immediate & Delayed (typical delay 4 months) & Immediate \\
\hline Adjustable & Yes & No & No & No \\
\hline Reversible & Yes & No & No & No \\
\hline Bilateral treatment & Yes & No & Yes & No \\
\hline Implanted devices & Yes & No & No & No \\
\hline Other considerations & $\begin{array}{l}\text { Device maintenance and } \\
\text { programming }\end{array}$ & $\begin{array}{l}\text { MRI guided } \\
\text { Skull penetration }\end{array}$ & Radiation & Variable thermal dosing \\
\hline
\end{tabular}

ET, essential tremor; DBS, deep brain stimulation; FUS, focused ultrasound; GKRS, gamma knife radiosurgical thalamotomy; RF, radiofrequency. 


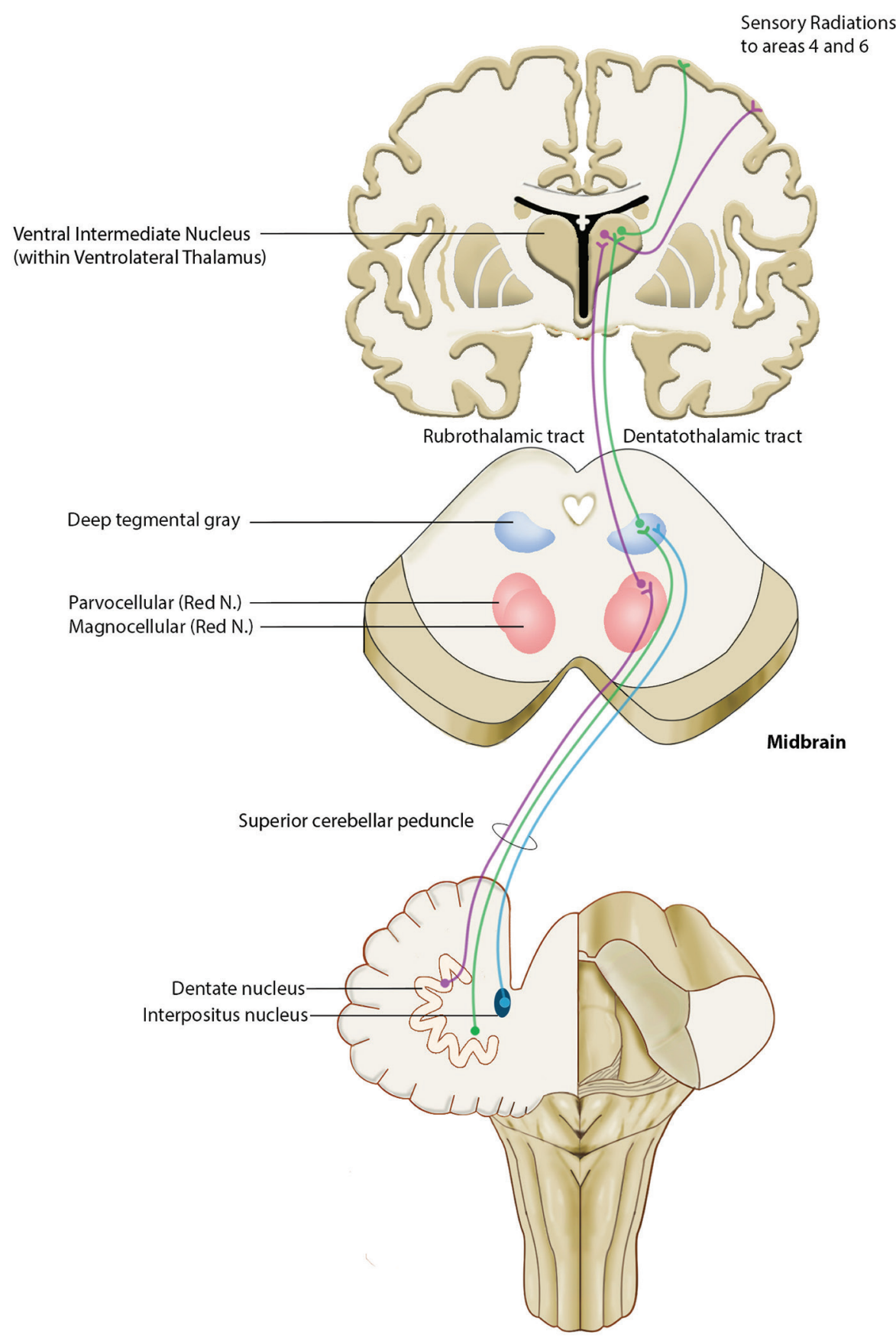

Figure 1 Diagram of dentatorubrothalamic tract. Fibres arising from the contralateral dentate and interposed cerebellar nuclei project superiorly through the superior cerebellar peduncle. Some fibres synapse in the magnocellular portion of the red nucleus before continuing to the thalamus (rubrothalamic tract) and some fibres continue to the ventrolateral thalamus (dentatothalamic tract). These fibres synapse in a somatotopic fashion in the ventral intermediate thalamic nucleus, Vim. From the Vim, thalamocortical fibres pass through the superior thalamic radiation to the motor and premotor cortex (Brodman's Area 4 and 6).

in voice tremor in 26 patients treated with caudal zona incerta DBS. There are reports of up to $75 \%$ improvement in head tremor and $60 \%$ in voice tremor 5 years after DBS implantation. ${ }^{19}$ Bilateral DBS had similar results in improving action tremor ranging from $66.0 \%$ to $73.8 \% .{ }^{9}{ }^{17}$ Among patients with bilateral thalamic DBS, ADLs were improved by $31.7 \%$ after 5 years. ${ }^{22}$ However, despite a greater overall reduction in tremor with bilateral thalamic DBS, some studies suggest little difference in disability or quality of life compared with unilateral treatments. ${ }^{10}$
Since cerebellothalamic connections are thought to be important in tremor circuits, the PSA/cZI has been targeted for stimulation among patients with ET. Some investigators suggest that PSA/cZI DBS may have an advantage over Vim DBS in reducing side effects from stimulation. ${ }^{23}$ Although the number of PSA/cZI case series is smaller, it has been posited as an equally effective, ${ }^{24}$ but more efficient target, requiring less energy consumption from DBS systems. ${ }^{23-25}$

Case series have demonstrated a $62 \%-95 \%$ reduction $^{26} 27$ in overall tremor within the first year in unilateral PSA/cZI DBS 
and a $75.9 \%-80.1 \%$ reduction in tremor in bilateral cases. ${ }^{23} 28$ Within the first 5 years after implantation, a similar reduction in efficacy has been demonstrated in unilateral $(52.4 \%-81 \%$ reduction $)^{29} 30$ and bilateral $\left(73.8 \%\right.$ reduction) cases. $^{31}$ Unilateral and bilateral PSA/cZI DBS have similar 1 year upper extremity tremor and ADL outcomes.

Thalamic DBS is not without potential complications (online supplementary table 2). Electrode insertion can cause clinically significant intracerebral haemorrhage in $0.5 \%-1.5 \%$ of cases. Moreover, there is a risk of wound infection (1.7\%-5.4\%), and hardware-related complications, such as lead fracture or migration (1.4\%-3.8\%). ${ }^{32}$ The most common neurological side effects of thalamic DBS are stimulation-induced paraesthesias, dysarthria and ataxia. Multiple studies have demonstrated that these side effects are more common with bilateral than with unilateral DBS. ${ }^{1933}$ Dysarthria has been reported in $11 \%-38.5 \%$ of patients with unilateral DBS, ${ }^{34} 35$ compared with $22 \%-75 \%$ of bilateral thalamic DBS. ${ }^{122236}$ Dysphasia is also more prevalent in bilateral $(18.8 \%)$ compared with unilateral $(9.9 \%)$ cases. ${ }^{34}$ Hypophonia has been reported in predominantly bilateral thalamic DBS cases (5\% unilateral, $18.8 \%$ bilateral). ${ }^{34}$ Bilateral thalamic DBS also has higher rates of ataxia $(56 \%-85.7 \%)^{12} 34$ compared with unilateral cases $(9.1 \%-16.7 \%)^{22} 37$ Other less common potential side effects are transient hemiparesis (unilateral: $4.5 \%,{ }^{37}$ bilateral: $6.7 \%$ ) and paraesthesias (unilateral: $4.5 \%-45 \%{ }^{12} 37$ bilateral: $5.9 \%{ }^{38}$ ). There are also reports of worsening verbal fluency, but not working memory or cognitive inhibition. ${ }^{39}$ The potential side effects of PSA/cZI are similar to that of Vim DBS. Complication rates related to DBS device insertion and maintenance are theoretically similar between PSA/cZI and Vim DBS. However, since most PSA/cZI DBS case series report using lower therapeutic stimulation voltages, stimulation related side effects of PSA/cZI DBS may potentially be lower than Vim DBS. Further studies are needed to fully clarify whether PSA/cZI DBS has fewer stimulation related side effects than Vim DBS.

Neurological side effects from DBS surgery can be related to an insertion effect at the time of surgery or they can be related to stimulation once the device is turned on. Typically, side effects from insertion subside within a few weeks after surgery; however, stimulation-related side effects can persist while the device is turned on. When neurological side effects are caused by stimulation, adjustments to the parameters can be made to optimise tremor suppression while minimising neurological effects.

There is some evidence that initial reduction in tremor lessens over time, due to disease progression rather than loss of stimulation effect. While Vim DBS has excellent tremor reduction and quality of life outcomes in the short-term, Shih et al reported that among a retrospective cohort of 45 patients, $73 \%$ had a waning benefit at some point during a 5 -year follow-up. ${ }^{40}$ In long-term follow-up studies among patients who underwent unilateral Vim DBS, tremor reduction was reported at $31 \%-46 \% .^{111214}$ In patients who received bilateral Vim DBS, long-term outcomes demonstrated a $48 \%$ reduction in overall tremor scores. ${ }^{1622}$ In these circumstances, DBS devices can be reprogrammed to further control tremor, although results are not always satisfactory. ${ }^{41}$

\section{Radiofrequency thalamotomy}

Various methods for localising and creating lesions within the ventrolateral thalamus have been described for Parkinson's disease and other tremor disorders since the 1950s and were effective for controlling tremor. Among these early lesioning methods were chemothalamotomy, cryothalamotomy, electrolytic lesioning and RF thalamotomy. ${ }^{42-46}$ RF thalamotomy was popularised because titrating thermal doses were consistent to apply across patients. ${ }^{45}$

$\mathrm{RF}$ thalamotomy is performed through a standard frontal burr hole and involves brain penetration with an RF probe. Microelectrode recordings can be used to refine targeting via mapping of the ventrolateral thalamus. During the final targeting process, the RF probe can be used as an electrical stimulator to test for tremor arrest and for the presence of unwanted side effects. The RF probe can be heated to subablative thermal temperatures, thereby producing a 'test lesion'. Once a permanent lesion is performed at the appropriate target, the effects on tremor suppression are immediately evident.

Many of the early studies describing the results of RF thalamotomy report results from a variety of tremor aetiologies, with Parkinson's disease being most common and ET included to a lesser extent. ${ }^{47-51}$ Studies that have selected only patients with ET have been published. ${ }^{52}{ }^{53}$ Among these studies, most were retrospective case series; however, there are notable exceptions including prospective studies with blinded patient evaluations. We included 15 studies with a total number of 278 patients with ET (range 6-65) that received RF thalamotomy. Among the studies that we analysed, reported improvement in tremor or percentage responders ranged from $49 \%$ to $100 \%$ with a majority of studies reporting 65\%-90\% improvement (online supplementary table 3). ${ }^{47-56}$ Zirh et al described a cohort study of 21 patients who underwent Vim thalamotomy for ET, who were evaluated blindly preoperatively and at 3 and 12 months postoperatively. Functional assessments involved speech, hygiene, eating, drinking, dressing, writing and work tasks. Among this cohort, $90 \%$ of patients had improvements in their tremor. Akbostanci et al examined the results of 37 patients with ET who underwent Vim thalamotomy. Immediately following surgery, tremor was reduced in all patients, while at last follow-up, tremor was absent in $61 \%$ of patients and mild without functional impairment in another 14\%.

Surgical complications from RF thalamotomies have been well documented and include sensory disturbances, hemiparesis, dysarthria, ataxia, gait disturbances, confusion, cognitive decline and intracerebral haemorrhage among others (online supplementary table 4). Since the RF ablation process can cause swelling surrounding the permanent lesion, many of the side effects from RF thalamotomy are transient and improve as the oedema subsides. Jankovic et al reported transient weakness in 34\%, transient dysarthria in $29 \%$ and transient confusion in $20 \%$ among 60 patients. ${ }^{50}$ Most of these complications resolved early in the postoperative recovery. Permanent side effects were less common. Pahwa et al reported a $6 \%$ rate of paraesthesia after RF thalamotomy among 17 patients, whereas Tasker et al reported a higher rate among their patient cohort with PD and ET (42\%) among 45 patients. ${ }^{54} 57$ Permanent ataxia or gait difficulty $(5 \%)$ was reported by Mohadjer et al. ${ }^{48}$ Dysarthria was reported in $8.9 \%$ of patients by Tasker et al and in $4.7 \%$ of patients by Nagaseki et al. ${ }^{4754}$ Several studies noted tremor recurrence after RF thalamotomy. Akbostanci et al reported five patients who underwent reoperation for recurrence with satisfactory results out of a total of 43 patients. Early recurrences were likely due to small lesions, lesions that were placed off target or due the presence of perilesional oedema that subsides over time. Late recurrences have been reported and considered to be secondary to disease progression.

\section{Gamma knife radiosurgery thalamotomy}

One of Leksell's original aims in designing the Gamma Knife (GK) was for non-invasive treatment of functional and movement 
disorders. ${ }^{5859}$ However, his original vision has been largely overshadowed by the successes of GK in neuro-oncology, trigeminal neuralgia and arteriovenous malformation treatment. ${ }^{6061}$ So far, only GK has been used for thalamotomy among patients with ET, while linear accelerators have been used for thalamotomy in pain and parkinsonian tremor. ${ }^{6162}$

During GK thalamotomy, patients are placed in a stereotactic frame under local anaesthetic. Typically, a single central maximal dose of 130-152 Gy using a $4 \mathrm{~mm}$ collimator is administered to the Vim. Optimal planning minimises radiation exposure to the internal capsule. ${ }^{63-70}$

Most of the studies that we included were uncontrolled, retrospective and unblinded case series, which totalled approximately 350 unique patients from seven centres worldwide. These patients often had significant medical comorbidities necessitating anticoagulants (which can be continued during GK), had refused DBS or previously underwent unsuccessful DBS or RF. ${ }^{63-70}$

Overall, the reduction of action tremor ranges from $7 \%$ to $61 \%$ and $3 \%$ to $68 \%$ at $3-9$ months and last-follow-up, respectively (median of 7-152 months) (online supplementary table $5)$. The study with the best description of the blinded outcome assessment yielded the lowest success rate in terms of tremor reduction. Lim et al performed blinded patient assessments and found only a 7\% improvement in tremor scores in 14 patients. ${ }^{65}$ Forty-five per cent to $100 \%$ of patients reported some degree of improvement and tremor arrest in 0\%-78\% of patients. Wide variations were also reported in improvement in writing (9\%-70\%), drawing (12\%-68\%), drinking (25\%-57\%) and pouring $(-5-87 \%) \%)$. Tremor improvement was retained in the long term (4-10y) in $80 \%-88 \%$ of patients. ${ }^{6672}$ Only one series, on bilateral stereotactic radiosurgery (SRS), included a quality of life measure (Karnovsky Performance Score, KPS), which significantly improved $43 \%-65 \%$ following the first SRS session and $76 \%$ following the second SRS session.

Several authors suggest that staged bilateral SRS thalamotomy can be performed safely, although the documented experience is limited to only 51 patients with ET. ${ }^{64667073}$ No adverse events reported after the second SRS session. ${ }^{6670}$ However, in non-ET SRS, serious adverse events, including coma and death from aspiration pneumonia, have been reported with bilateral SRS thalamotomy. ${ }^{7475}$

Permanent side effects (most frequently hemiparesis, followed by paraesthesia, dysphasia and dysphagia) were relatively rare complications (median 0\%; range 0\%-18\%) and no deaths were reported. Side effects were observed years after SRS in two patients; a haemorrhagic stroke occurred in the irradiated area in patients taking anticoagulants for atrial fibrillation. ${ }^{65} 76$ One case of delayed, complex involuntary movements has been reported. ${ }^{77}$ However, transient side effects including paraesthesia, dysphasia, dysphagia and hemiparesis were more common (median 2\%; range 0\%-9\%) (online supplementary table 6).

A major drawback of RS for ET is the lack of intraoperative clinical or electrophysiological aids to account for differences between individuals. ${ }^{78}$ Tractography can be of benefit to localise the Vim and internal capsule during target planning. ${ }^{79-82}$ The delayed therapeutic effect is another important issue; benefits may not be present up to 1 year after SRS, with a median time of approximately 4 months. ${ }^{63-70}$

\section{MR-guided focused ultrasound thalamotomy}

FUS was first used as a treatment for movement disorders in 1959 by Meyers and Fry; ${ }^{44} 83$ however, broader applications of FUS were hindered by the need for an acoustic window through the skull to transmit ultrasound (US) energy into the brain. Developments in FUS transducer design and CT-based skull correction algorithms for phase shift allow successful transcranial US delivery. ${ }^{84-90}$ This has led to a resurgence of interest in FUS treatments for movement disorders, particularly ET.

During FUS thalamotomy procedures, the patient's head is completely shaved and fixed within a stereotactic frame that is coupled to an US transducer. The patient is brought into the MRI where the procedure takes place under image guidance. The Vim nucleus is targeted stereotactically, and US energy is delivered in progressive doses until focal target temperatures are achieved, causing permanent cell death. The procedure is monitored with magnetic resonance thermometry, and the patient is awake for intraprocedural tremor assessments.

From 2013 to 2017, eight studies using FUS for the treatment of ET were identified that included a total of 151 patients (range 4-76). ${ }^{91-97}$ Among these studies, seven were uncontrolled prospective case series (OCEM level 4 evidence). After favourable results from three independent pilot studies were described, ${ }^{91} 9394$ Elias et al performed a multi-institutional, double-blind randomised control trial with sham treatment conditions. This study enrolled 76 patients and demonstrated a reduction in the mean tremor score at 3 months of $47 \%$, compared with only $0.1 \%$ reduction in the sham treatment group. At 12 months, the reduction in tremor score in the treatment group was 35\%, compared with $2 \%$ in the sham group (online supplementary table 1$).^{92}$

Tremor severity and quality of life were assessed pretreatment and at intervals postoperatively with the Clinical Rating Scale for Tremor (CRST) and Quality of Life in Essential Tremor questionnaire (QUEST). The duration of postoperative follow-up ranged from 3 to 12 months. Of note, all studies demonstrated a significant reduction in overall CRST scores at all time points (online supplemental table 7). No studies with results longer than 2 years have been reported thus far.

Out of the 151 treated patients in the eight studies included, the most commonly encountered adverse effects were paraesthesias involving the face, lips or fingers $(27 \%$ of patients in total, $19 \%$ transient, $8 \%$ persistent beyond 1 month). ${ }^{92}$ This is secondary to inadvertent heating of the adjacent somatosensory thalamus. The second most common complication was ataxia and gait instability (23\% overall, 19\% transient, 4\% persistent). Many patients with ET have mild gait disturbances preoperatively, which are temporarily worsened after thalamotomy. More uncommonly, transient (2\%) and persistent (2\%) hand or face weakness was apparent due to heating of the internal capsule (online supplementary table 8). Other less common complications were transient ischaemic attack, hypogeusia, persistent finger dysaesthesia and deep venous thrombosis requiring anticoagulation (1\% each). Among current reports, eight patients $(7.5 \%)$ experienced treatment failure secondary to insufficient heating at the target to create an ablation. ${ }^{91-94}$

\section{DISCUSSION}

\section{Comparative studies}

In head-to-head comparisons of DBS and RF thalamotomy for tremor, there was equipoise in terms of tremor control. Schuurman et al reported a prospective, randomised trial comparing unilateral RF and DBS for severe tremor of several aetiologies (Parkinson's disease (PD), ET and multiple sclerosis (MS)). The overall results for tremor control were not significantly different between the two groups in the short-term; however, there were more adverse events among the patients 
who underwent thalamotomy compared with DBS. ${ }^{98}$ Schuurman et al also presented a 5 -year follow-up report from this patient cohort. ${ }^{99}$ This study concluded that both treatments were effective in treating tremor, although the effects of stimulation decreased at later time points among patients with ET.

Pahwa et al reported a retrospective case-control series comparing unilateral RF and DBS among patients with ET. ${ }^{57}$ In this study, 35 patients received RF thalamotomy; 18 patients were excluded from analysis (three patient deaths, one unsuccessful procedure, five prior thalamic surgeries and nine insufficient data). The 17 remaining patients were matched to a group of patients who underwent DBS surgery $(n=17$, from 81 patients). There were not any differences in the tremor outcome scores between patients who received thalamotomy vs patients who received DBS after short-term follow-up (2.2 and 3.1 months, respectively). The authors also concluded that the surgical complications were higher among patients who received thalamotomy compared with DBS. These studies helped popularised DBS as a treatment for tremor.

Patient factors in determining treatment

During the natural history of ET, many patients may experience asymmetric symptoms with tremor more severely affecting or disabling one upper extremity. In these circumstances, patients may elect to undergo unilateral DBS surgery or a thalamotomy procedure to treat the affected upper extremity. Tremor in the contralateral side often progresses and may warrant additional surgical treatment. In these circumstances, DBS is the best option since several studies have reported unacceptably high rates of neurological deficits in speech, swallowing and cognition following bilateral thalamic lesioning procedures (figure 2).

\begin{tabular}{|ll|}
\hline Aremor symptoms & Treatments \\
\hline Unilateral tremor & $\begin{array}{l}\text { 1. Unilateral DBS } \\
\text { 2. Unilateral FUS, GK or RF thalamotomy }\end{array}$ \\
Bilateral tremor & $\begin{array}{l}\text { 1. } \\
\text { Bilateral DBS (Single or staged } \\
\text { surgery) } \\
\text { 2. Unilateral DBS for dominant or more } \\
\text { affected upper extremity with delayed } \\
\text { staging for secondary DBS } \\
\text { 3nilateral DBS followed by RF or GK } \\
\text { thalamotomy }\end{array}$ \\
\hline
\end{tabular}

\section{Patients unwilling or unable to undergo DBS}

Significant medical comorbidities

Skull favorable for FUS

Infection of DBS system

\section{Treatments}

- GKRS thalamotomy

- FUS thalamotomy

- RF, GKRS, or FUS thalamotomy

Figure 2 Surgical treatment recommendations for essential tremor. (A) For patients with predominant unilateral tremor symptoms; contralateral DBS or thalamotomy with RF, FUS or GKRS are all surgical options. For eligible patients with bilateral tremor symptoms who wish to have both upper extremities treated, bilateral DBS can be performed safely. Bilateral thalamic DBS can be offered in a single operation, in a staged fashion or in a delayed staged fashion (months or years after initial surgery). For patients who received unilateral DBS and whose contralateral symptoms progress or become disabling, staged contralateral DBS is an option. Among patients received unilateral DBS but who do not want to undergo secondary DBS surgery, RF or GKRS thalamotomy procedures can be performed. For patients who have had infections or do not want additional implanted devices RF thalamotomy is a good option. For patients who are elderly, who are taking anticoagulants or who have general medical conditions that do not permit open surgical procedures, GKRS thalamotomy is a good treatment option. (B) Among patients who refuse DBS treatment for ET, patients with poor medical condition may be eligible for GKRS thalamotomy. For patients with favourable ultrasound penetrating skull characteristics, FUS thalamotomy is an option, and for patients with prior infected DBS systems, RF thalamotomy can be performed. ET, essential tremor; DBS, deep brain stimulation; FUS, focused ultrasound; GKRS, gamma knife radiosurgical; $\mathrm{RF}$, radiofrequency. 
Among patients with severe bilateral ET, DBS can be safely used bilaterally to treat tremor involving both upper extremities or with axial symptoms such as head or voice tremor. Many patients are satisfied with unilateral treatment of their dominant or more severely affected upper extremity, although many tasks require bimanual dexterity. Some surgeons advocate implanting bilateral thalamic DBS leads in a staged fashion to decrease the likelihood of complications. Although bilateral Vim DBS has been shown to improve overall tremor scores more than unilateral DBS or thalamotomy, it remains unclear whether bilateral treatment improves the overall quality of life in ET. ${ }^{10}$

Despite the long history of efficacy and safety of DBS surgery for movement disorders, many patients with ET may be reluctant to undergo DBS. Previous studies among patients with ET suggest that this patient population may be relatively risk adverse. ${ }^{6}{ }^{100}$ Accordingly, some patients may elect to undergo thalamotomy procedures secondary to a perception that these procedures are less invasive, have fewer side effects or for concerns regarding permanent device implantation and related complications with DBS. Thus, thalamotomy procedures such as FUS and GKRS may initially appeal to patients with ET who might otherwise avoid or forego treatment, but as stated above a detailed discussion of risks/benefits is critical as many of the perceptions of risk for DBS and safety of FUS may be unfounded or incorrect.

In patients who are reluctant to undergo DBS, FUS, RF and GKRS thalamotomy are reasonable options (figure 2). Thalamotomy procedures may be appealing to patients who are interested in a single-encounter treatment. These patients may be unwilling or unable to attend multiple clinical appointments for DBS device programming or long-term device maintenance. There is strong evidence to support the effectiveness of FUS in tremor control among patients with ET, although some have criticised the reported complication rates. ${ }^{92} 101$ Some patients may not be candidates for FUS thalamotomy. These patients include those whose skulls do not permit US transmission or whose anatomy had been altered by previous neurosurgery and patients who have contraindications to MRI such as pacemaker devices and extreme claustrophobia. RF or GKRS thalamotomy may be a good surgical option for these patients. GKRS thalamotomy has also been suggested for patients who would otherwise be at risk for open surgical procedures such as bleeding disorders, history of infections or increased perioperative medical risk factors.

\section{Other considerations}

Tremor recurrence after surgery has been recognised among many of the early thalamotomy studies and was frequently treated with repeat thalamotomy procedures. Recent FUS thalamotomy trials reported waning effects of thalamotomy over 12 month follow-up. RF and FUS thalamotomy operations must balance adequate treatment of the surgical target to ameliorate tremor completely versus the added risk that overtreatment could cause permanent damage to important adjacent neural structures. Tremor recurrence has also been reported among patients treated with DBS who have been followed clinically for long durations. In these circumstances, DBS settings can be adjusted to optimise outcomes. Features of long-term benefit from DBS include older age at surgery, more severe tremor, anteriorly placed electrodes and increased single unit beta power detected by MER at surgery. ${ }^{102}$

One of the most important factors in achieving quality surgical outcomes for patients with ET is avoiding serious perioperative adverse events. These include intracerebral haemorrhages, seizures, new neurological symptoms, cognitive impairments and medical complications related to surgery. GKRS has the fewest reported serious complications and is among the safest surgical procedures for ET. FUS and RF create permanent lesions within the brain and new neurological deficits have been reported. Among patients treated with FUS, transient gait instability and paraesthesias were commonly reported. For patients treated with RF thalamotomy, ataxia, hemiparesis, dysarthria and cognitive decline have been reported. Since DBS does not create permanent tissue destruction, it is largely reversible; this improves its safety profile.

\section{Future directions}

Advances in DBS device technology are aimed to improve some of the drawbacks of DBS therapy. Developments in the intracranial electrode now have additional lead contacts and directional electrical currents, which enable more sophisticated and selective electrical fields to interact with the target brain structures. These features allow further flexibility with device programming, which can maximise beneficial electrical stimulation while minimising disabling side effects. For Vim DBS, this may improve stimulation-related side effects such as motor contractions or paraesthesias. Second, developments in internal pulse generator technology are on the horizon that will improve their longevity and may obviate the need for extension wires or subcutaneous chest implants.

Currently, thalamic DBS therapy is delivered continuously; however, for many patients with ET, symptoms are only present during manual tasks. Continuous stimulation can potentially cause negative side effects such as dysarthria and imbalance. Recently, there has been an effort in the movement disorder field to apply adaptive or closed-loop DBS for Parkinson's disease and ET. In these systems, central or peripheral sensors of abnormal brain activity can be used to detect tremor states and apply electrical currents selectively. For patients with ET, an implanted surveillance sensor could detect when a patient was planning or beginning a movement associated with tremor, and the DBS device could deliver an electric current to inhibit tremor. Such closed loop systems could conserve energy and further reduce potential complications of DBS.

Advances in neuroimaging allow for more precise visualisation of the white matter tracts around the thalamus. Diffusion tensor imaging (DTI) can be used to map large white matter tracts such as the internal capsule, medial lemniscus and dentatorubrothalamic tract. These studies can be used during stereotactic procedures to improve targeting and potentially make lesional operations, like FUS thalamotomy, safer.

\section{CONCLUSION}

When discussing the surgical options for patients with ET, we advocate for presenting the merits and drawbacks for the surgical modalities that the patient is a good candidate to receive. Since DBS has been safely used for decades, it is considered by many surgeons and neurologists to be the treatment of choice for most patients with medically refractory or severe ET. RF thalamotomy has also been used for decades and has been shown to be as effective in controlling tremor. However, RF thalamotomy has been associated with a higher complication rate than DBS. GKRS thalamotomy has been performed for several decades by several groups, but has received some criticism since there are no means for intraprocedural target confirmation and delayed treatment effects. FUS thalamotomy is the newest modality for tremor 
treatment and has received attention since it has transcranial capabilities, immediate effects and the potential for procedural target refinement. FUS thalamotomy studies have been criticised for tremor recurrence and the high incidence of paraesthesia and gait disturbance. These factors should be carefully considered by both neurosurgeon and patients when selecting an appropriate treatment for ET.

Contributors RFD: Research project: conception, organisation, execution Manuscript: writing of the first draft, review and critique. DJL, PVD, AFa: Research project: execution; Manuscript: review and critique. $\mathrm{CH}, \mathrm{MH}, \mathrm{SKK}, \mathrm{AFo}$ : Research project: organisation; Manuscript: review and critique. AML: Research project: conception, execution; Manuscript: review and critique.

Funding The authors have not declared a specific grant for this research from any funding agency in the public, commercial or not-for-profit sectors.

Competing interests PDV has received grants for research from Research Fund Flanders (FWO) and the European Society for Stereotactic and Functional Neurosurgery (ESSFN) and grants for education and travel from the World Society of Stereotactic and Functional Neurosurgery (WSSFN), Medtronic and St. JudeAbbott. AML is a consultant for Medtronic, Boston Scientific and Insightech. Alfonso Fasano is a consultant for Abbvie, Medtronic, Boston Scientific, Sunovion, Chiesi farmaceutici, UCB, Ipsen.

Patient consent Not required

Provenance and peer review Not commissioned; externally peer reviewed.

Open access This is an open access article distributed in accordance with the Creative Commons Attribution Non Commercial (CC BY-NC 4.0) license, which permits others to distribute, remix, adapt, build upon this work non-commercially, and license their derivative works on different terms, provided the original work is properly cited, appropriate credit is given, any changes made indicated, and the use is non-commercial. See: http://creativecommons.org/licenses/by-nc/4.0/.

\section{REFERENCES}

1 Findley LJ. Epidemiology and genetics of essential tremor. Neurology 2000;54(Suppl 4):S8-S13.

2 Louis ED, Ferreira JJ. How common is the most common adult movement disorder? Update on the worldwide prevalence of essential tremor. Mov Disord 2010;25:534-41.

3 Deuschl G, Wenzelburger R, Löffler K, et al. Essential tremor and cerebellar dysfunction clinical and kinematic analysis of intention tremor. Brain 2000;123(Pt 8):1568-80

4 Louis ED, Gillman A, Boschung S, et al. High width variability during spiral drawing: further evidence of cerebellar dysfunction in essential tremor. Cerebellum 2012;11:872-9.

5 Tröster Al, Pahwa R, Fields JA, et al. Quality of life in Essential Tremor Questionnaire (QUEST): development and initial validation. Parkinsonism Relat Disord 2005; 11:367-73.

6 Lorenz D, Schwieger D, Moises H, et al. Quality of life and personality in essential tremor patients. Mov Disord 2006;21:1114-8.

7 Zesiewicz TA, Elble RJ, Louis ED, et al. Evidence-based guideline update: Treatment of essential tremor: Report of the Quality Standards Subcommittee of the American Academy of Neurology. Neurology 2011;77:1752-5.

8 Zesiewicz TA, Elble R, Louis ED, et al. Practice parameter: therapies for essential tremor: report of the Quality Standards Subcommittee of the American Academy of Neurology. Neurology 2005;64:2008-20.

9 Graff-Radford J, Foote KD, Mikos AE, et al. Mood and motor effects of thalamic deep brain stimulation surgery for essential tremor. Eur J Neurol 2010;17:1040-6.

10 Huss DS, Dallapiazza RF, Shah BB, et al. Functional assessment and quality of life in essential tremor with bilateral or unilateral DBS and focused ultrasound thalamotomy. Movement Disorders 2015;30:1937-43.

11 Blomstedt P, Hariz G-M, Hariz Ml, et al. Thalamic deep brain stimulation in the treatment of essential tremor: a long-term follow-up. Br J Neurosurg 2007:21:504-9.

12 Pahwa R, Lyons KE, Wilkinson SB, et al. Long-term evaluation of deep brain stimulation of the thalamus. J Neurosurg 2006;104:506-12.

13 Lyons KE, Pahwa R, Busenbark KL, et al. Improvements in daily functioning after deep brain stimulation of the thalamus for intractable tremor. Movement Disorders 1998;13:690-2.

14 Nazzaro JM, Pahwa R, Lyons KE. Long-term benefits in quality of life after unilateral thalamic deep brain stimulation for essential tremor. J Neurosurg 2012;117:156-61.

15 Obwegeser AA, Uitti RJ, Turk MF, et al. Thalamic stimulation for the treatment of midline tremors in essential tremor patients. Neurology 2000;54:2342-4.

16 Cury RG, Fraix V, Castrioto A, et al. Thalamic deep brain stimulation for tremor in Parkinson disease, essential tremor, and dystonia. Neurology 2017;89:1416-23.
17 Pilitsis JG, Metman LV, Toleikis JR, et al. Factors involved in long-term efficacy of deep brain stimulation of the thalamus for essential tremor. J Neurosurg 2008;109:640-6.

18 Mandat T, Koziara H, Rola R, et al. Thalamic deep brain stimulation in the treatment of essential tremor. Neurol Neurochir Pol 2011;45:37-41.

19 Sydow Oet al. Multicentre European study of thalamic stimulation in essential tremor: a six year follow up. J Neurol Neurosurg Psychiatry 2003;74:1387-91.

20 Koller WC, Lyons KE, Wilkinson SB, et al. Efficacy of unilateral deep brain stimulation of the VIM nucleus of the thalamus for essential head tremor. Mov Disord 1999; 14:847-50

21 Hägglund P, Sandström L, Blomstedt P, et al. Voice Tremor in Patients with Essential Tremor: Effects of Deep Brain Stimulation of Caudal Zona Incerta. J Voice 2016;30:228-33.

22 Baizabal-Carvallo JF, Kagnoff MN, Jimenez-Shahed J, et al. The safety and efficacy of thalamic deep brain stimulation in essential tremor: 10 years and beyond. J Neurol Neurosurg Psychiatry 2014;85:567-72

23 Plaha P, Patel NK, Gill SS. Stimulation of the subthalamic region for essential tremor. J Neurosurg 2004;101:48-54

24 Barbe MT, Liebhart L, Runge M, et al. Deep brain stimulation of the ventral intermediate nucleus in patients with essential tremor: Stimulation below intercommissural line is more efficient but equally effective as stimulation above. Exp Neurol 2011:230:131-7.

25 Sandvik U, Hariz G-M, Blomstedt P. Quality of life following DBS in the caudal zona incerta in patients with essential tremor. Acta Neurochir 2012;154:495-9.

26 Blomstedt P, Sandvik U, Hariz MI, et al. Influence of age, gender and severity of tremor on outcome after thalamic and subthalamic DBS for essential tremor. Parkinsonism Relat Disord 2011;17:617-20.

27 Blomstedt P, Sandvik U, Tisch S. Deep brain stimulation in the posterior subthalamic area in the treatment of essential tremor. Mov Disord 2010;25:1350-6.

28 Plaha P, Khan S, Gill SS. Bilateral stimulation of the caudal zona incerta nucleus for tremor control. J Neurol Neurosurg Psychiatry 2008;79:504-13.

29 Fytagoridis A, Sandvik U, Åström M, et al. Long term follow-up of deep brain stimulation of the caudal zona incerta for essential tremor. J Neurol Neurosurg Psychiatry 2012:83:258-62.

30 Murata J-ichi, Kitagawa M, Uesugi H, et al. Electrical stimulation of the posterior subthalamic area for the treatment of intractable proximal tremor. J Neurosurg 2003;99:708-15

31 Plaha P, Javed S, Agombar D, et al. Bilateral caudal zona incerta nucleus stimulation for essential tremor: outcome and quality of life. J Neurol Neurosurg Psychiatry 2011:82:899-904.

32 Fenoy AJ, Simpson RK. Risks of common complications in deep brain stimulation surgery: management and avoidance. J Neurosurg 2014;120:132-9.

33 Rehncrona S, Johnels B, Widner $\mathrm{H}$, et al. Long-term efficacy of thalamic deep brain stimulation for tremor: double-blind assessments. Mov Disord 2003;18:163-70

34 Alomar S, King NK, Tam J, et al. Speech and language adverse effects after thalamotomy and deep brain stimulation in patients with movement disorders: A meta-analysis. Mov Disord 2017;32:53-63.

35 Barbe MT, Dembek TA, Becker J, et al. Individualized current-shaping reduces DBSinduced dysarthria in patients with essential tremor. Neurology 2014:82:614-9.

36 Matsumoto JY, Fossett T, Kim M, et al. Precise stimulation location optimizes speech outcomes in essential tremor. Parkinsonism Relat Disord 2016;32:60-5.

37 Peng-Chen Z, Morishita T, Vaillancourt D, et al. Unilateral thalamic deep brain stimulation in essential tremor demonstrates long-term ipsilateral effects. Parkinsonism Relat Disord 2013;19:1113-7.

38 Zhang K, Bhatia S, Oh MY, et al. Long-term results of thalamic deep brain stimulation for essential tremor. J Neurosurg 2010;112:1271-6.

39 Pedrosa DJ, Auth M, Pauls KAM, et al. Verbal fluency in essential tremor patients: the effects of deep brain stimulation. Brain Stimul 2014:7:359-64.

40 Shih LC, LaFaver K, Lim C, et al. Loss of benefit in VIM thalamic deep brain stimulation (DBS) for essential tremor (ET): how prevalent is it? Parkinsonism Relat Disord 2013;19:676-9.

41 Picillo M, Lozano AM, Kou N, et al. Programming deep brain stimulation for tremor and dystonia: the Toronto Western Hospital Algorithms. Brain Stimul 2016;9:438-52.

42 Narabayashi H, Okuma T, Shikiba S. Procaine oil blocking of the globus pallidus. Arch Neurol Psychiatry 1956;75:36-48.

43 Cooper IS. Chemopallidectomy and chemothalamectomy for parkinsonism and dystonia. Proc R Soc Med 1959:52:47-60.

44 Meyers R, Fry WJ, Fry FJ, et al. Early experiences with ultrasonic irradiation of the pallidofugal and nigral complexes in hyperkinetic and hypertonic disorders. J Neurosurg 1959;16:32-54.

45 Sweet WH, Mark VH, Hamlin H. Radiofrequency lesions in the central nervous system of man and cat: including case reports of eight bulbar pain-tract interruptions. $J$ Neurosurg 1960;17:213-25.

46 Dallapiazza R, McKisic MS, Shah B, et al. Neuromodulation for movement disorders. Neurosurg Clin N Am 2014;25:47-58

47 Nagaseki Y, Shibazaki T, Hirai T, et al. Long-term follow-up results of selective VIMthalamotomy. J Neurosurg 1986;65:296-302. 
48 Mohadjer M, Goerke H, Milios E, et al. Long-term results of stereotaxy in the treatment of essential tremor. Stereotact Funct Neurosurg 1990;54-55:125-9.

49 Goldman MS, Ahlskog JE, Kelly PJ. The symptomatic and functional outcome of stereotactic thalamotomy for medically intractable essential tremor. J Neurosurg 1992;76:924-8.

50 Jankovic J, Cardoso F, Grossman RG, et al. Outcome after stereotactic thalamotomy for parkinsonian, essential, and other types of tremor. Neurosurgery 1995;37:680-7. discussion 86-7.

51 Shahzadi S, Tasker RR, Lozano A. Thalamotomy for essential and cerebellar tremor. Stereotact Funct Neurosurg 1995;65:11-17.

52 Akbostanci MC, Slavin KV, Burchiel KJ. Stereotactic ventral intermedial thalamotomy for the treatment of essential tremor: results of a series of 37 patients. Stereotact Funct Neurosurg 1999;72:174-7.

53 Zirh A, Reich SG, Dougherty PM, et al. Stereotactic thalamotomy in the treatment of essential tremor of the upper extremity: reassessment including a blinded measure of outcome. J Neurol Neurosurg Psychiatry 1999;66:772-5.

54 Tasker RR. Deep brain stimulation is preferable to thalamotomy for tremor suppression. Surg Neuro/ 1998;49:145-53. discussion 53-4.

55 Niranjan A, Jawahar A, Kondziolka D, et al. A comparison of surgical approaches for the management of tremor: radiofrequency thalamotomy, gamma knife thalamotomy and thalamic stimulation. Stereotact Funct Neurosurg 1999;72:178-84.

56 Sobstyl M, Zabek M, Koziara $\mathrm{H}$, et al. [Stereotactic ventrolateral thalamotomy in the treatment of essential tremor]. Neurol Neurochir Pol 2006;40:179-85.

57 Pahwa R, Lyons KE, Wilkinson SB, et al. Comparison of thalamotomy to deep brain stimulation of the thalamus in essential tremor. Movement Disorders 2001:16:140-3.

58 Leksell L. The stereotaxic method and radiosurgery of the brain. Acta Chir Scand 1951;102:316-9.

59 Leksell L. Cerebral radiosurgery. I. Gammathalanotomy in two cases of intractable pain. Acta Chir Scand 1968:134:585-95.

60 Friehs GM, Park MC, Goldman MA, et al. Stereotactic radiosurgery for functional disorders. Neurosurg Focus 2007;23:E3.

61 Frighetto L, De Salles A, Wallace R, et al. Linear accelerator thalamotomy. Surg Neurol 2004;62:106-13.

$62 \mathrm{Kim}$ W, Sharim J, Tenn S, et al. Diffusion tractography imaging-guided frameless linear accelerator stereotactic radiosurgical thalamotomy for tremor: case report. J Neurosurg 2018;128:1-7.

63 Kondziolka D, Ong JG, Lee JYK, et al. Gamma Knife thalamotomy for essential tremor. J Neurosurg 2008;108:111-7.

64 Kooshkabadi A, Lunsford LD, Tonetti D, et al. Gamma knife thalamotomy for tremor in the magnetic resonance imaging era. J Neurosurg 2013;118:713-8.

65 Lim SY, Hodaie M, Fallis M, et al. Gamma knife thalamotomy for disabling tremor: a blinded evaluation. Arch Neurol 2010;67:584-8.

66 Niranjan A, Raju SS, Kooshkabadi A, et al. Stereotactic radiosurgery for essential tremor: retrospective analysis of a 19-year experience. Movement Disorders 2017;32:769-77.

67 Ohye C, Higuchi Y, Shibazaki T, et al. Gamma Knife thalamotomy for Parkinson disease and essential tremor: a prospective multicenter study. Neurosurgery 2012;70:526-35. discussion 35-6.

68 Tuleasca C, Witjas T, Najdenovska E, et al. Assessing the clinical outcome of Vim radiosurgery with voxel-based morphometry: visual areas are linked with tremor arrest! Acta Neurochir 2017;159:2139-44.

69 Witjas T, Carron R, Krack P, et al. A prospective single-blind study of Gamma Knife thalamotomy for tremor. Neurology 2015;85:1562-8.

70 Young RF, Li F, Vermeulen S, et al. Gamma Knife thalamotomy for treatment of essential tremor: long-term results. J Neurosurg 2010;112:1311-7.

71 Campbell AM, Glover J, Chiang VLS, et al. Gamma knife stereotactic radiosurgical thalamotomy for intractable tremor: a systematic review of the literature. Radiotherapy and Oncology 2015;114:296-301.

72 Young RF, Jacques S, Mark R, et al. Gamma knife thalamotomy for treatment of tremor: long-term results. J Neurosurg 2000;93(Suppl 3):128-35.

73 Kann BH, Yu JB, Stahl JM, et al. The impact of cobalt-60 source age on biologically effective dose in high-dose functional Gamma Knife radiosurgery. J Neurosurg 2016;125(Suppl 1):154-9.

74 Duma CM. Movement disorder radiosurgery--planning, physics and complication avoidance. Prog Neuro/ Surg 2007:20:249-66.

75 Okun MS, Stover NP, Subramanian T, et al. Complications of gamma knife surgery for Parkinson disease. Arch Neurol 2001;58:1995-2002.
76 Rothstein TL. A late complication of $\gamma$ knife radiosurgery. Rev Neurol Dis 2010:7:150-1. discussion 57-9.

77 Siderowf A, Gollump SM, Stern MB, et al. Emergence of complex, involuntary movements after gamma knife radiosurgery for essential tremor. Movement Disorders 2001;16:965-7.

78 Sato S, Ohye C, Shibazaki T, et al. Neurophysiological evaluation of the optimum target in gamma thalamotomy: indirect evidence. Stereotact Funct Neurosurg 2005:83:108-14.

79 Gomes JG, Gorgulho AA, de Oliveira López A, et al. The role of diffusion tensor imaging tractography for Gamma Knife thalamotomy planning. J Neurosurg 2016;125(Suppl 1):129-38.

80 Lefranc M, Carron R, Regis J. Prelemniscal radiations: a new reliable landmark of the thalamic nucleus ventralis intermedius location? Stereotact Funct Neurosurg 2016;93:400-6

81 King NKK, Krishna V, Basha D, et al. Microelectrode recording findings within the tractography-defined ventral intermediate nucleus. J Neurosurg 2017;126:1669-75

82 Sammartino F, Krishna V, King NKK, et al. Tractography-based ventral intermediate nucleus targeting: novel methodology and intraoperative validation. Mov Disord 2016:31:1217-25.

83 Fry FJ. Precision high intensity focusing ultrasonic machines for surgery. Am J Phys Med Rehabil 1958:37:152???156-6.

84 Clement GT, Hynynen K. A non-invasive method for focusing ultrasound through the human skull. Phys Med Biol 2002;47:1219-36.

85 Clement GT, Sun J, Giesecke T, et al. A hemisphere array for non-invasive ultrasound brain therapy and surgery. Phys Med Biol 2000;45:3707-19.

86 Clement GT, White J, Hynynen K. Investigation of a large-area phased array fo focused ultrasound surgery through the skull. Phys Med Biol 2000;45:1071-83.

87 Clement GT, White PJ, King RL, et al. A magnetic resonance imaging-compatible, large-scale array for trans-skull ultrasound surgery and therapy. J Ultrasound Med 2005;24:1117-25.

88 Hynynen K, Clement GT, McDannold N, et al. 500-element ultrasound phased array system for noninvasive focal surgery of the brain: A preliminary rabbit study with ex vivo human skulls. Magn Reson Med 2004;52:100-7.

89 Hynynen K, McDannold N, Clement G, et al. Pre-clinical testing of a phased array ultrasound system for MRI-guided noninvasive surgery of the brain-A primate study. Eur J Radiol 2006;59:149-56.

90 Hynynen K, Freund WR, Cline HE, et al. A clinical, noninvasive, MR imagingmonitored ultrasound surgery method. Radiographics 1996;16:185-95.

91 Chang WS, Jung HH, Kweon EJ, Zadicario E, et al. Unilateral magnetic resonance guided focused ultrasound thalamotomy for essential tremor: practices and clinicoradiological outcomes. J Neurol Neurosurg Psychiatry 2015;86:257-64.

92 Elias WJ, Lipsman N, Ondo WG, et al. A randomized trial of focused ultrasound thalamotomy for essential tremor. N Engl J Med Overseas Ed 2016;375:730-9.

93 Elias WJ, Huss D, Voss T, Loomba J, et al. A pilot study of focused ultrasound thalamotomy for essential tremor. N Engl J Med Overseas Ed 2013;369:640-8.

94 Lipsman N, Schwartz ML, Huang Y, Lee L, et al. MR-guided focused ultrasound thalamotomy for essential tremor: a proof-of-concept study. Lancet Neurol 2013;12:462-8

95 Gallay MN, Moser D, Rossi F, et al. Incisionless transcranial MR-guided focused ultrasound in essential tremor: cerebellothalamic tractotomy. J Ther Ultrasound 2016;4:5

96 Kim M, Jung NY, Park CK, et al. Comparative evaluation of magnetic resonanceguided focused ultrasound surgery for essential tremor. Stereotact Funct Neurosurg 2017:95:279-86.

97 Zaaroor M, Sinai A, Goldsher D, et al. Magnetic resonance-guided focused ultrasound thalamotomy for tremor: a report of 30 Parkinson's disease and essentia tremor cases. J Neurosurg 2018;128:1-9.

98 Schuurman PR, Bosch DA, Bossuyt PMM, et al. A comparison of continuous thalamic stimulation and thalamotomy for suppression of severe tremor. N Engl I Med Overseas Ed 2000;342:461-8.

99 Schuurman PR, Bosch DA, Merkus MP, et al. Long-term follow-up of thalamic stimulation versus thalamotomy for tremor suppression. Mov Disord 2008;23:1146-53.

100 Thenganatt MA, Louis ED. Personality profile in essential tremor: a case-control study. Parkinsonism Relat Disord 2012;18:1042-4.

101 Alterman RL. One step backward: Magnetic resonance guided focused ultrasound thalamotomy for the treatment of medically refractory tremor. Ann Neurol 2017:81:348-50.

102 Sandoe C, Krishna V, Basha D, et al. Predictors of deep brain stimulation outcome in tremor patients. Brain Stimul 2018:11:592-9. 